\title{
Acupuncture and asthma: a review of controlled trials
}

J Kleijnen, G ter Riet, P Knipschild

\begin{abstract}
Background Published controlled trials of acupuncture in asthma have often contained a small number of subjects and the results are contradictory. Controlled trials have been reviewed to determine whether clearer conclusions could be obtained by assessing as many studies as possible according to methodological criteria.
\end{abstract}

Methods A literature search produced 13 trials on the efficacy of acupuncture in the treatment of patients with asthma. These studies were reviewed on the basis of 18 predefined methodological criteria. A maximum of 100 points for study design could be earned in three main categories: (a) adequate study population, (b) adequate intervention, and (c) adequate measurement of effects.

Results The quality of even the eight better studies (more than $50 \%$ of the maximum score) proved to be mediocre. No study earned more than $72 \%$ of the maximum score. The results from the better studies are highly contradictory. Conclusions Claims that acupuncture is effective in the treatment of asthma are not based on the results of well performed clinical trials.

In many countries acupuncture is one of the most popular forms of alternative medicine. No less than $22 \%$ of the general practitioners in the Netherlands believe that acupuncture is to some extent efficacious in the treatment of asthma. ${ }^{1}$ For other purposes, such as aiding attempts at giving up smoking and treatment of chronic pain, an even larger number (up to half) believe that acupuncture is efficacious. ${ }^{1}$ This belief is not, however, supported by evidence from controlled trials. Reviews of the evidence of the effects of acupuncture on giving up smoking and on chronic pain show a clear trend, the results becoming more negative as the methodological quality of the trials increases. ${ }^{23}$

Here we present the results of controlled trials in asthma. We emphasise the quality of study design, performance, and presentation. The review deals with the question of whether there is compelling evidence from clinical research that acupuncture is efficacious in asthma.
Methods

METHODOLOGICAL ASPECTS OF RESEARCH ON ACUPUNCTURE AND ASTHMA

In making a diagnosis of asthma assessment of physical symptoms and lung function is very important. Asthma is often divided into intrinsic and extrinsic asthma, and parallel descriptive terms, such as asthma with or without atopy, reversible obstructive airway disease, and exercise induced asthma, are also used. In 1962 the American Thoracic Society published criteria for the diagnosis of asthma. ${ }^{4}$ For controlled trials the description of the diagnostic criteria for the selection of patients must be clear. A description of the severity of the symptoms (dyspnoea, cough, wheeze, duration of disease, frequency of attacks, and daily use of medication) and of lung function (forced expiratory volume, forced vital capacity, peak expiratory flow rate, etc) should also be given so that the reader has an impression of the kind of patients participating in the trial. It is an advantage if the study population is fairly homogeneous as this helps to ensure prognostic similarity at the baseline of the subpopulations allocated to active and placebo treatment.

When subjective symptoms are the main outcome measure substantial improvements in patients in the control group can be expected, and relatively large groups with a similar prognosis at the baseline are needed for valid assessment of efficacy. It is difficult to estimate the number of patients needed for a study to be informative and valid, as the smaller the number of subjects the less confidence can be placed in the randomisation procedure and the more likely it will be that known or unknown confounders are unequally divided between the treatment groups. We chose "at least 50 patients/group" as one of the criteria for methodological soundness. To increase the luck of the draw, it makes sense first to stratify according to prognosis and then to randomise within each stratum. Blocking ensures that an equal number of patients is allocated to each treatment group. In addition, publication bias is less likely for experiments with large numbers of participants: the effort and costs of the study will increase the likelihood that a paper is submitted for publication and published. ${ }^{5}$ Other major criteria for methodological soundness are randomisation and blindness. When prognostic indicators are insufficiently known or difficult to measure, random alloca- 
tion to the contrasted treatments is a major help in ensuring prognostic similarity. Blindness of the patients is important to ensure that the intervention is exactly the same in the contrasted groups except for the active acupuncture treatment. Even the acupuncturist can be blinded if the person who determines the treatment is not the person who inserts the needles, and if irrelevant acupuncture points (acupoints) are used in the control group.

In published studies two kinds of placebo treatment have been given to the control group. Needles can be inserted in the skin at places where no acupoints have been described (placebo points), or they can be inserted in acupoints that are not relevant for the patient's complaints (irrelevant points). For an unbiased measurement of the effects of treatment both the patient and the assesser should be blind. This is particularly important when the relief of subjective symptoms is the end point, as is partially the case here.

\section{IDENTIFICATION AND SELECTION OF RELEVANT STUDIES}

A Medline online literature search covering 1963-89 (keywords acupuncture, clinical trials, asthma, therapy) was combined with additional Medline CD-ROM searches, screening of Excerpta Medica (1981-90; keyword acupuncture), and correspondence with and visits to colleagues. Journals of alternative medicine were screened with the help of a title service bulletin of the National Centre for Information and Documentation on Alternative Medicine in the Netherlands.

Efforts were also made initially to translate Russian papers, but the English abstracts suggested that the methods were always disappointingly poor. We therefore decided to exclude Russian papers unless the words "random allocation" or "double blind" were mentioned in the English abstract (this never occurred). Screening some of the recent Chinese papers available in English (in the Journal of Traditional Chinese Medicine) yielded only case series and no controlled trials.

Studies included in this review fulfil the following criteria. (1) Needles were used: studies in which only surface electrodes or laser acupuncture were used were excluded; studies on electroacupuncture were included so long as needles were used. (2) A reference group was used (either some sort of sham procedure or an existing treatment modality, or both). Fourteen publications on the efficacy of acupuncture in the treatment of patients with asthma were identified. One was excluded, however, because it was a double publication, ${ }^{6}$ leaving 13 papers for further analysis. ${ }^{7-19}$ These were scored on the basis of a list consisting of 18 predefined methodological criteria (table). Two of the authors (JK and GtR) scored these publications independently.

Assessment of the papers using these criteria gives an indication of the methodological quality of the trials. This quality is an important factor in weighing the conclusions of different trials and should bear on the impact of all the evidence presented on the reader's opinion. The total score (table) should be considered only as a quick reference to the methodological quality, and does not presuppose some sort of numerical equality among the different criteria. It could be argued that other criteria or other weight factors should be used for the methodological assessment and that this kind of assessment is rather subjective. We have, however, selected well established methodological criteria, ${ }^{2021}$ and our assessment can be checked by the reader (table).

\section{Results}

At no time did inconsistencies in assigning the scores exceed 10 points (from a total of 100 ); they were usually due to reading errors of one of the reviewers, which were then corrected. The results are shown in the table. Reading the table vertically gives a picture of the methodological quality of each paper. Horizontal reading gives an impression of the characteristics of controlled clinical research on acupuncture and asthma. Striking features are the inadequate numbers of patients and lack of prestratification (matching), which is mandatory when the number of participants is small. There was often inadequate follow up after treatment, lack of assessment of subjective symptoms, and the use of medication was checked inadequately or not at all. Data presentation was often limited to such an extent that the analyses could not be checked, and side effects were often not mentioned.

Eight of the 13 studies scored more than 50 points on our list, ${ }^{912-14} 16-19$ though the best study obtained only $72 \%$ of the maximum score of $100 .{ }^{16}$ This indicates the rather poor quality of the papers. The outcome of a trial was regarded as "positive" if acupuncture produced better results than the sham treatment according to the authors (as in more than half of the studies the information presented was not adequate to enable us to check the analysis, we had to rely on the conclusions of the authors). Only three of the eight studies reporting positive results scored more than $\mathbf{5 0}$ points. In contrast, all five studies reporting negative results scored over 50 .

\section{Discussion}

In only one study was the effect of individually tailored acupuncture treatment, as taught by the traditional Chinese textbooks (classical acupuncture), assessed. ${ }^{15}$ In the others needles were placed at the same points in all patients (formula acupuncture); this is the form of acupuncture practised most frequently in Western countries. The underlying philosophy in formula acupuncture is that patients with the same (Western) diagnosis are similar enough to be treated with needling of the same acupoints. The traditional acupuncturist will disagree with this approach, claiming that every patient is unique and consequently must be treated differently, on the basis of the experience of thousands of years. Our problem with this approach is that it lacks logic. If every patient 
Criteria used to assess the trials of acupuncture in asthma reviewed, with scores assigned (maximum possible score 100) *

\begin{tabular}{|c|c|c|c|c|c|c|c|c|c|c|c|c|c|}
\hline Criteria & Berger $^{7}$ & $\begin{array}{l}\text { Taki- } \\
\text { shima }^{8}\end{array}$ & Virsik $^{9}$ & $L u u^{10}$ & $Y u^{n}$ & $\begin{array}{l}\text { Christen- } \\
\text { sen }^{12}\end{array}$ & Chow $w^{13}$ & Tandon ${ }^{14}$ & $J o b s t^{15}$ & Dias $^{16}$ & Tashkin ${ }^{17}$ & Fung ${ }^{18}$ & Tashkin \\
\hline \multicolumn{14}{|l|}{ METHODOLOGICAL CRITERIA } \\
\hline Homogeneity $\dagger$ (3) & - & - & - & - & - & - & 3 & 3 & 2 & - & - & 3 & - \\
\hline Prestratification $\ddagger$ (3) & - & - & - & - & - & - & - & - & 3 & - & - & - & - \\
\hline Random allocation (12) & - & - & - & 12 & - & 12 & 12 & 12 & 12 & 12 & 12 & 12 & 12 \\
\hline $\begin{array}{l}\text { Similarity in relevant respects } \\
\text { at baseline (2) }\end{array}$ & - & 1 & 1 & 1 & 2 & 2 & 2 & - & 2 & 2 & - & 2 & 2 \\
\hline At least 50 patients/group (10) & - & - & - & - & - & - & - & - & - & - & - & - & - \\
\hline No more than $20 \%$ lost to & & & & & & & & & & & & & \\
\hline follow & 5 & 3 & 5 & 5 & 5 & 5 & 5 & 5 & 5 & 5 & 5 & 5 & 5 \\
\hline \multicolumn{14}{|l|}{ Adequate intervention } \\
\hline control avoided§ (2) & 一 & - & - & - & - & - & - & - & - & - & - & - & - \\
\hline $\begin{array}{l}\text { Acupuncture procedure } \\
\text { adequately described\| (10) }\end{array}$ & 5 & 10 & 10 & 10 & 10 & 10 & 10 & 10 & - & 5 & 10 & 10 & 10 \\
\hline $\begin{array}{l}\text { Good quality of acupuncture } \\
\text { mentioned } \star \star \star \\
(15)\end{array}$ & - & - & - & - & 8 & - & - & 5 & 15 & 15 & 15 & 15 & 15 \\
\hline $\begin{array}{l}\text { Existing treatment modality used } \\
\text { in control group }+\dagger(3)\end{array}$ & - & - & - & - & - & - & - & - & - & - & 3 & - & - \\
\hline \multicolumn{14}{|l|}{ Adequate measurement of effects } \\
\hline $\begin{array}{l}\text { Patients blinded (10) } \\
\text { Evaluator blinded (5) }\end{array}$ & $\underline{2}$ & 10 & - & $\overline{5}$ & 10 & $\begin{array}{r}10 \\
5\end{array}$ & 10 & $\begin{array}{r}10 \\
5\end{array}$ & $\begin{array}{l}5 \\
5\end{array}$ & $\begin{array}{l}5 \\
5\end{array}$ & $\begin{array}{r}10 \\
5\end{array}$ & 10 & $\begin{array}{r}10 \\
5\end{array}$ \\
\hline $\begin{array}{l}\text { Follow up after treatment at } \\
\text { least } 3 \text { months } \pm(5)\end{array}$ & 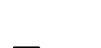 & 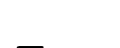 & - & - & - & & - & $=$ & & & & & \\
\hline $\begin{array}{l}\text { least } 3 \text { monthsł‡ (5) } \\
\text { Subjective symptoms and }\end{array}$ & - & - & - & - & - & - & - & - & - & - & - & - & - \\
\hline ks recorded (3) & - & 1 & - & - & 3 & 3 & - & - & 3 & 3 & - & - & 3 \\
\hline Use of medication noted (2) & - & - & - & - & - & 2 & - & - & - & 2 & - & - & 2 \\
\hline Lung function values given (3) & 1 & 1 & 3 & 3 & 3 & 2 & 3 & 3 & 3 & 2 & 3 & 3 & 3 \\
\hline Side effects mentioned (2) & - & - & 2 & - & 2 & - & 2 & 2 & - & - & 1 & 2 & - \\
\hline $\begin{array}{l}\text { Reader able to do inferential } \\
\text { statistics (5) }\end{array}$ & - & - & 5 & - & - & - & 5 & - & 5 & 5 & - & 5 & 5 \\
\hline TYPE OF ASTHMA & - & Inf/mix & Mod & Mod & - & St & $\begin{array}{l}\text { Ex, } \\
\text { atopic }\end{array}$ & $\begin{array}{l}\text { Mod/ } \\
\text { sev, } \\
\text { atopic }\end{array}$ & $\mathrm{Br}$ & Ch & $\begin{array}{l}\text { Mild/ } \\
\text { mod }\end{array}$ & $\begin{array}{l}\text { Mild/ } \\
\text { mod }\end{array}$ & $\begin{array}{l}\text { Mod/ } \\
\text { sev }\end{array}$ \\
\hline $\begin{array}{l}\text { CONTROL TREATMENT } \\
\text { SCORE }\end{array}$ & $\begin{array}{l}\text { Irr } \\
16\end{array}$ & $\begin{array}{l}\text { Plac } \\
26\end{array}$ & $\begin{array}{l}\text { Plac } \\
31\end{array}$ & $\begin{array}{l}\text { Plac } \\
36\end{array}$ & $\begin{array}{l}\text { Plac } \\
43\end{array}$ & $\begin{array}{l}\text { Plac } \\
51\end{array}$ & $\begin{array}{l}\text { Irr } \\
52\end{array}$ & $\begin{array}{l}\text { Irr } \\
55\end{array}$ & $\begin{array}{l}\text { Plac } \\
60\end{array}$ & $\begin{array}{l}\text { Irr } \\
61\end{array}$ & $\begin{array}{l}\text { Plac } \\
64\end{array}$ & $\begin{array}{l}\text { Irr } \\
67\end{array}$ & $\begin{array}{l}\text { Plac } \\
72\end{array}$ \\
\hline OUTCOME OF TRIAL & Pos & Pos & Pos & Pos & Pos & Neg & Neg & $\mathrm{Neg}$ & Pos & Neg & Pos & Pos & $\mathrm{Neg}$ \\
\hline
\end{tabular}

${ }^{\star}$ Half of the maximum score (rounded up) for any criterion was given if the reviewers agreed that the report was not clear on the particular criterion or if the criterion was only partly met.

$\dagger$ This criterion was scored with great caution because it requires considerable knowledge about which factors are prognostically relevant and opinions in this respect vary widely.

tThis was always scored if the authors mentioned it, irrespective of prognostic relevance.

§The phenomenon of extrasegmental counterirritation that could cause sham acupuncture procedures (not at acupoints) to be active placebos. ${ }^{22} 23$

$\|$ This was scored only if the acupoints used, the number of minutes per treatment, the interval between treatments, and total duration of treatment were mentioned.

${ }_{\star}$ This is difficult but important to assess; if no positive results are found proponents of acupuncture might claim that treatment was administered by inexperienced or badly educated acupuncturists.

$\dagger+$ Before a new treatment is implemented its efficacy must be compared with that of other existing treatments.

\pm+ Defined as the time from the last treatment to the last measurement of effects.

Inf/mix-infectious or mixed; mod-moderate; st-stable; ex-exercise induced; br-breathlessness (patients had chronic obstructive pulmonary disease and only four had features of asthma); ch-chronic; sev-severe; irr-irrelevant acupuncture points; plac-placebo acupuncture points; pospositive; neg-negative.

indeed is unique, nobody will know how to treat a new patient and experience will then be of little help. The inevitable conclusion must be that even traditional acupuncturists apply some kind of formula acupuncture; the criteria for placing patients in the same treatment category are probably much stricter, however. New research on more homogeneous study populations on the basis of classical acupuncture diagnosis might be informative.

Some authors claim that sham acupuncture could be an active placebo. According to acupuncture theory, however, therapeutic results are produced only by needle insertions at very specific point locations. If stimulation of any location can be efficacious, detailed study of the acupuncture theory does not appear to be necessary. We think that few proponents of acupuncture would agree with this idea.

Unfortunately, we could not be blinded in assigning a methodological score to every paper. We were already too familiar with the publications before we started to score them. This means that some degree of reviewer bias cannot be excluded. The reader, however, can check our assignment of points and apply different weights to different criteria, to see whether the methodological assessment would be substantially changed-though we think that it would not. Meta-analysis is becoming fashionable. In our opinion too much emphasis is put on statistical pooling of study results. Criteria for deciding whether modes of treatment, patients with different degrees of disease, and end points are similar enough to be pooled are not yet available. The rationale of criteria based meta-analysis ${ }^{24}$ is that it makes no sense to combine data from good research with data from bad research. We did not pool the results of the studies because the material is too 
heterogeneous and of insufficient quality. Horizontal reading of table 2 shows the major drawbacks of existing studies. Future experiments should have more homogeneous study populations, larger numbers of patients, longer follow up, more attention given to the assessment of subjective symptoms and the use of medication, and better presentation of the data.

In the meantime, we must conclude that no studies of high quality seem to have been published and that claims of the efficacy of acupuncture in the treatment of asthma are not supported by the results of well performed clinical trials. The existing evidence, as presented here, is at best contradictory.

This study was supported by a grant (project No 87-35) from the Dutch Ministry of Welfare, Public Health, and Cultural Affairs.

1 Knipschild P, Kleijnen J, Riet ter G. Belief in the efficacy of alternative medicine among general practitioners in The Netherlands. Soc Sci Med 1990;31:625-6.

2 Riet ter G, Kleijnen J, Knipschild P. A meta-analysis of studies into the effect of acupuncture on addiction. $\mathrm{Br} \mathrm{J}$ Gen Pract 1990;40:379-82.

3 Riet ter G, Kleijnen J, Knipschild P. Acupuncture and chronic pain. A criteria-based meta-analysis. J Clin Epidemiol 1990;43:1191-9.

4 American Thoracic Society. Chronic bronchitis, asthma, and pulmonary emphysema: a statement by the committee on diagnostic standards for non-tuberculous respiratory disease. Am Rev Respir Dis 1962;85:762-8.

5 Easterbrook PJ, Berlin JA, Gopalan R, Matthews DR. Publication bias in clinical research. Lancet 1991;337: 867-72.

6 Christensen PA, Laursen LC, Taudorf E, Sørensen SC, Weeke B. Akupunktur til asthmapatienter. Ugeskr Laeger 1986;148:241-3.

7 Berger D, Nolte D. Hat Akupunktur einen nachweisbaren bronchospasmolytischen Effekt beim Asthma bronchiale? Med Klin 1975;70:1827-30.
8 Takishima T, Mue S, Tamura G, Ishihara T, Watanabe K. The bronchodilating effect of acupuncture in patients with acute asthma. Ann Allergy 1982;48:44-9.

9 Virsik K, Krištúfek P, Bangha O, Urban S. The effect of acupuncture on pulmonary function in bronchial asthma. Prog Respir Res 1980;14:271-5.

10 Luu M, Maillard D, Pradalier A, Boureau F. Contrôle spirométrique dans la maladie asthmatique des effets de la puncture de points douloureux thoraciques. Respiration 1985;48:340-5.

11 Yu DYC, Lee SP. Effect of acupuncture on bronchial asthma Clin Sci Molec Med 1976;51:503-9.

12 Christensen PA, Laursen LC, Taudorf E, Sørensen SC Weeke B. Acupuncture and bronchial asthma. Allergy 1984;39:379-85.

13 Chow OKW, So SY, Lam WK, Yu DYC, Yeung CY. Effect of acupuncture on exercise-induced asthma. Lung 1983; $161: 321-6$.

14 Tandon MK, Soh PFT. Comparison of real and placebo acupuncture in histamine-induced asthma. A doubleblind crossover study. Chest 1989;96:102-5.

15 Jobst K, McPherson K, Brown V, Fletcher HJ, Mole P Chen $\mathrm{JH}$, et al. Controlled trial of acupuncture for disabling breathlessness. Lancet 1986;ii:1416-9.

16 Dias PLR, Subramaniam S, Lionel NDW. Effects of acupuncture in bronchial asthma: preliminary communication. $J$ $R$ Soc Med 1982;75:245-8.

17 Tashkin DP, Bresler DE, Kroening RJ, Kerschner H, Katz $\mathrm{RL}$, Coulson A, et al. Comparison of real and simulated acupuncture and isoproterenol in methacholine-induced asthma. Ann Allergy 1977;39:379-87.

18 Fung KP, Chow OKW, So SY. Attenuation of exerciseinduced asthma by acupuncture. Lancet 1986;ii:1419-22.

19 Tashkin DP, Kroening RJ, Bresler DE, Simmons M, Coulson AH, Kerschner $\mathrm{H}$, et al. A controlled trial of real and simulated acupuncture in the management of chronic asthma. J Allergy Clin Immunol 1985;76:855-64.

20 Meinert CL. Clinical trials: design, conduct, analysis. New York: Oxford University Press, 1986.

21 Feinstein AR. Clinical epidemiology: the architecture of clinical research. Philadelphia: Saunders, 1985.

22 Willer JC, Roby A, Le Bars D. Psychophysical and electrophysiological approaches to the pain relieving effects of heterotopic nociceptive stimuli. Brain 1984;107: 1095-112.

23 Le Bars D, Willer JC [letter]. Pain 1988;32:259-60.

24 Fletcher RH, Fletcher SW, Wagner EH. Clinical epidemiology. Baltimore: Williams and Wilkins, 1988:226-40. 